\title{
Curating a fan history of vampires: 'What We Vid in the Shadows' at VidUKon 2016
}

\section{Charlotte Stevens}

\section{Birmingham City University}

\author{
Abstract \\ At the 2016 fan convention VidUKon, I curated and screened a vidshow themed around \\ vampires. A vidshow is a curated programme of fanvids, fan-made video art pieces that \\ adapt television and film sources into short videos, which is shown at media fan \\ conventions. To plan this, I first selected vampire-related examples from my research \\ collection, and then drafted a list of screen vampires to guide my search for other vids to \\ address gaps. From there, my curation was guided by a series of questions about how these \\ pocket-sized adaptations would contribute to the vidshow's representation of screen \\ vampires. How do these act as a history of media fandom's relationship with screen \\ vampires? Vids are works of textual analysis that offer critical and creative responses to \\ their source texts. What would my selection argue about how we watch vampires? I \\ propose that vidshows are a site of negotiating fan-favourite and cult canons of vampire \\ shows and characters.
}

\section{Keywords}

fanvids

media fandom

vampires

curation 
television

memory

\section{Contact:}

Birmingham Centre for Media and Cultural Research, Birmingham City University, The Parkside Building, 5 Cardigan Street, Birmingham B4 7BD, UK.

E-mail: charlotte.stevens@bcu.ac.uk

This article reflects on the process and context for curating a vidshow about vampires in film and television. This practice-based research builds on my doctoral work (Stevens 2015), in which I examined a selection of individual vids, but did not consider the potential meanings created by their exhibition in convention screenings. This research is also the result of a coincidence of timing in which a call for programming for VidUKon was followed closely by a call for articles at the International Vampire Film and Arts Festival. While I have attended a number of fan conventions and watched many vidshows as part of my doctoral research, I had not previously attempted to contribute any programming of my own. Curating the vidshow 'What We Vid in the Shadows' at VidUKon 2016 was a chance to put into practice what I had observed and experienced about what makes an effective vidshow. This article is based on the experience of curating the vampire-focused vidshow itself, observations made during my research into vids and vidding, and my personal experiences in and around vidding fandom that preceded my academic interest in this area. This curation involved identifying, collecting and programming an hour of fanvids short fan-made videos that re-use existing media - which each had something to do with 
screen vampires. As every fanvid (henceforth 'vid') is made by recombining film and television sources into a new work, taking Colin McCabe's definition of an adaptation as a work 'that relies for some of its material' on an already-extant text (2011: 3), vids can easily be understood as adaptations. Those who produce vids ('vidders') take video sources from their own collections of media, condensing and reframing them into new works that offer critical and/or creative perspectives on texts.

Vids are derived from television and film sources, and approximate the music video form in appearance and duration. They are non-commercial fan works, predominantly made by women, ${ }^{1}$ which construct creative and critical analyses of existing media, and have been produced since the early 1980s. There is an increasing academic interest in vids and vidding, which frame these found-footage works as a unique fan practice embedded in a discursive context of returning to, and commenting on, existing media texts (see Coppa 2008; Ng 2008; Turk and Johnson 2012; Nadkarni 2017). Jonathan Gray has argued that vids offer a look at a fan's 'path through a text' (2010:161) similar to marginalia, with each clip chosen revealing notable moments in a larger work. Each vid is therefore a record of how a text has been watched or read. As Linda Hutcheon has argued, 'adaptation is an act of appropriating or salvaging, and this is always a double process of interpreting and then creating something new' (2013: 20). Given the range of possible source material and array of potential paths to form, fanworks reveal an expansive definition of what a 'text' can be. In the case of a vidshow featuring vampires, both the specific films and series would be considered texts; the vidshow itself, as a curated programme of vids, is likewise a text. This could be a history of watching, interpretation or spectatorship - both individually and for a community of practice - as each vid offers its own record of how the 
vidder personally viewed a source text alongside how they want to present it to their audience. This could also be a history of technological use, as vids textualize traces of VCRs/PCs being used in creative/resistant ways by preserving the particular visual artefacts of the works' bootleg aesthetics (Stevens 2017). Vids can also be a point of access for histories of productive media fandom, both to situate individual works in their discursive contexts - see, for example, Coppa's (2008) history of early vidding, or Louisa Ellen Stein's (2010) analysis of religiously themed vids of Supernatural (2005-present) and to recognize the history of fans' curatorial work that has made it possible to access these objects.

I argue that vids provide a document of historical spectatorship that can be a productive modelling of how to do certain kinds of media history. Just as a potsherd can reveal histories of technical innovation and labour practices, of the development of the decorative arts or of trade networks and migration, so too can the study of a vid open up paths of inquiry in several directions. In this case, and taking on a less tangible metaphor, vids are arguably akin to adaptations that are recognized as such, and therefore 'are directly and openly connected to recognizable other works, and that connection is part of their formal identity' (Hutcheon 2013: 21). I am interested in how vids are simultaneously works in their own right, with their own hermeneutic/aesthetic potential, and objects that act as discursive loci for their source material. Taking this work as a case study, this article considers canon-formation and the memorialization of screen vampires as mediated through fannish discourse.

\section{Vids as adaptations, curating as interpretation}


As Thomas Leitch (2011) argues, the figure of the vampire offers a potent metaphor through which to consider the parasitic/collaborative nature of adaption. Perhaps more than other forms of adaptation, vids are manifestly new works made out of existing media. They offer themselves as intensifications of their source material. As Hutcheon observes, cross-media adaptations may often be 'reduced in size, and thus, inevitably, complexity' (2013: 36). However, she argues that rather than viewing this reduction as a 'subtraction' and therefore detrimental, in fact 'when plots are condensed and concentrated, they can sometimes become more powerful' (Hutcheon 2013: 36). Vids about vampires intensify and respond to their source texts both as a narrative intensification and in codification of recognizable tropes (teeth, blood, excessive desire). Many of the vids that I screened in preparing the vidshow included clips highlighting these tropes, clearly signalling the centrality of these moments in how their source films and series are remembered through vids.

Leitch argues that academic canons are a form of 'ministering to the undead' as popular tastes shift away from Classical allusions and leave literary re-workings as the key site for understanding adaptations as adaptations (2011: 14); the vidshow is a form of canon-formation as each vid included argues for the individual work's importance or notability. As association with an existing text is a key marketing strategy for adaptations (per Letich), the degree to which a vid's source material is well known was a factor in making my selection. Within vidding fandom, 'source' refers to the film, series or other visual material being adapted. A minority of vidshows are organized around their soundtrack rather than source, but in this instance my long list was guided by the visuals. A vidshow full of obscure sources would contain a certain set of pleasures, but a mix of the 
familiar and the strange (at least, according to the VJ) shows off the VJ's breadth of knowledge, presents unfamiliar texts as potential sites of affective engagement and allows for communal enjoyment of old favourites.

Through this process, I devised and refined a set of criteria that helped shape my selection. These were governed partially by aesthetic considerations, as guided by my knowledge and study of vids and vidshows. I chose to balance a personal overview of screen vampires that I remember fondly from my own teenage years (Lestat, and later, Spike) with a selection that reflected the breadth of possible available screen vampires. Again, as the vids are both objects unto themselves and also discursive loci for their source material, these decisions were as much about which vids to show, as they were about which source (adapted) texts had been interpreted in compelling ways. This resulted in a conscious decision to balance familiar and obscure sources, and to consider a few compelling vids where I knew the vid and not the source material. As a curatorial project, I wanted to attempt a representative sample of vampire characters as seen through vids, and use the vidshow to perform a history of media fandom's relationship with screen vampires for the convention attendees. Quality was another criterion: were the vids coherent, pleasurable or otherwise interesting? Could I have a range of tone and soundtrack choices or would I be working with the worst stereotype of dour goth metal?

While I was aware of the potential longevity of the vidshow as a historical record, my primary concern was to create something pleasurable for the audience who I expected to be present at the convention itself and using my experience in that subculture to guide selection. Accordingly, I knew that I needed to represent a range of fandoms, balancing the iconic with the obscure. Ultimately, I used a range of source material, from art house 
cinema to teen monster movies, with 'quality' and cult television, from five nations (United States, United Kingdom, Germany, New Zealand and Canada). This range also included a mix of soundtrack and tone, making it possible to shape a vidshow with different levels. The process revealed the sheer number of white male vampires that have captured the attention of vidding fans. To counter this tendency, I made sure to include more diverse representations where possible. Unfortunately, this was easier to accomplish with gender than with race; for example, while the premiering vid focuses on the dual female protagonists of Byzantium (Jordan, 2014), aside from Queen of the Damned (Rymer, 2002), the source material is overwhelmingly white.

I was also aware of how vids are works of textual analysis that offer critical and creative responses to their source texts: taken together, what would my selection argue about how we watch vampires? In each vid, the clip selection points to what might be notable with each text. For example, the Kindred: The Embraced (1996) vid takes great pleasure in cataloguing that series' adherence to certain standard tropes and iconic vampire moments. However, the majority of the vidshow is concerned with sympathetic vampires of the sort described by Nina Auerbach (1995), with vids looking into their motivations as individuals, and not as generic monsters. This is not to say that the overall feeling of the vidshow is an uncritical presentation of vampires as harmless friends to humans; instead, there is a tendency to show the life of a vampire as one in which considerable pleasures come at a cost. I additionally chose vids that focused on vampires or vampire-hunting. The Buffy the Vampire Slayer (1997-2003) and True Blood (2008-2014) vids in the vidshow refrain from even showing the TV series' primary protagonists (Buffy and Sookie, respectively) until at least 90 seconds into the vid. Both vids frame their 
adaptations away from their nominal protagonist to centre attention on supporting (vampiric, monstrous) characters, renegotiating our engagement with both narrative and its nostalgia as linked to these undead beings, and metaphorically creating new life from old.

\section{Vidshows and curation}

My purpose is to explore the idea of the vidshow as a historicizing activity, relating to memory and memorialization on the one hand and canon-formation and performances of taste on the other. Memory and canonization are closely related, and they offer access to the different ways in which histories of film, television and other media function within the fan convention space. For my purposes here, the vidshow itself can be easily read as a site for curating different adaptations of historical media, and constructing a canon out of these favoured objects. This performance of memorializing key works opens up a conceptual space in which to consider the curated context for the vids, revealing a historical context for individual vids that will be absent when viewing a single vid on its own.

It is common to encounter vids in isolation; as already suggested, this is also a common way to encounter vids in scholarly literature. You might stumble across a vid on YouTube, or have a friend share one with you, or notice when a vidder announces a new work on a blog or social media. When a vid goes viral, as a few have, it becomes even more disconnected from its context of production. However, when a number of vids are shown together at a convention, the curation and programming of a vidshow presents the opportunity to explore how these screenings interact with histories of screen media. A vidshow tends to be just under an hour long, with a programme of approximately a dozen 
vids. This has historically been one of the key exhibition contexts for the vid form; however, this screening format may now be on the wane. The vidding-focused convention VividCon, in announcing that its 2018 convention will be its last, noted that its vidshows had once been the only place to see high-resolution vids played on a big screen (renenet: 2017). Streaming high-definition video online has, understandably, changed vids' exhibition and distribution contexts. Nevertheless, curated programmes of vids defined VividCon, still define its sister convention VidUKon and form a part of programming at other conventions (such as Wiscon). These are not haphazardly constructed experiences, but a curated sequence either directed by a theme or composed out of ordering user-submitted works. While VividCon may have conceived of its purpose as a place to watch vids in a betterquality format than what might have been available to the home viewer, I have found that a key pleasure of convention screenings is in being a member of a live audience. Whatever the motivations, VividCon's vidshows arguably popularized the format for these curated programmes of vids.

My vampire vidshow is an example of a themed show; other examples from the vidding conventions include vids about westerns (at VividCon 2011), space (at VidUKon 2013) or using only Canadian-produced source material (at VividCon 2010). Themed vidshows could also be organized around the kinds of relationships or characters depicted (triads, teams), kinds of formal content (VividCon 2012's 'Let My Lyrics Go', programmed vids with instrumental soundtracks) or mood (VidUKon 2017's 'Make 'Em Laugh'). The overall idea is to create a coherent and novel experience - it would be bad form to duplicate vidshows entirely or even repeat many vids year to year - and to present a path for the audience to follow through the different interactions with the vidshow's theme. 
Following Amy Holdsworth's discussion of clip shows - television about television and that mode's relationship with nostalgia and history, I argue that the vidshow is similarly a site through which 'to consider the complex interplay between old and new' (2011: 96). Holdsworth argues that clip shows 'structures of and relations to the past can tell us more about television's own memory cultures and their influence on the construction of broader cultural memories' (2011: 96). Extending this, I propose that the vidshow is a collection of adapted, interpreted pieces of historical film and television. ${ }^{2}$ Being rather more than a clip show, a themed vidshow presents access to what could be understood as fandom's memory culture as each curated sequence of vids offers a metainterpretation (enacted through the vids chosen) of the chosen topic. Deciding the running order of the sequence is similar to making a mixtape; it is also creating a context in which to understand each vid, with an aim to allow each vid to engage in conversation with the next work in the sequence. This further level of mediation allows the audience to enjoy each vid itself, but also re-encounter each vid's source material in its new context.

\section{'What We Vid in the Shadows'}

To plan the vidshow, I first selected vids from my research collection that were made from vampire films and television series, and then drafted a list of screen vampires to guide my search for other vids to address gaps. Pleasingly, I found more vids than could fit in an hour's programming slot. More importantly, reflecting on the process of selection and curation proved useful in naming particular questions and assumptions arising from the process. Therefore, my evaluation and curation was guided by a series of questions about how these condensed adaptations of vampire films and series would contribute towards 
the argument produced by the vidshow about the representation of vampires in these media.

For example, how might I best balance a personal overview of my favourite screen vampires (Lestat, Spike) with a representative sample of vampire characters as seen through vids? How could this show act as a history of media fandom's relationship with screen vampires? The majority of films and television programmes represented in the vidshow were produced within the last twenty years; the vids made from older material are themselves recent productions. Also, as already stated, vids are works of textual analysis that offer critical and creative responses to their source texts. Taken together, what would my selection argue about how we watch vampires? Some of these questions were present at the start of the process and others emerged in curation.

As I was coming to this practice with a background in television studies, and a long history of participation in media fandom, I was struck by the resonances between Amy Holdsworth's work on 'nostalgia television', in which existing programmes and televised events are revisited (repackaged), and the vidshow as a fan-made site of media memorialization. Amy Holdsworth writes about the interplay of memory, remembering and encounters with the past as enacted by producers of nostalgia television, in which

a desire to remember may translate into the pleasures of recognition and deep forms of affection generated by nostalgia, yet this is tempered by the risk of nonrecognition or the disappointments of mis-remembering. Despite these variable 'payoffs' the pleasures of nostalgia television are driven by curiosity and anticipation: will it be how I remembered? (2011: 102) 
Conversely, vid may be the only way a viewer encounters its source material: it is possible to know a film or series only through its fannish mediations (vids, fanfiction, etc.), and the nostalgia of these encounters is therefore not necessarily for the source material itself. In this latter case, the source of these fannish adaptations becomes secondary to the suite of paratexts that surround it. It is not that these are orphaned texts, but offer a position for the indirect consumption of their source.

By the time I began my curation, the two annual vidding conventions had established certain norms about vidshows. ${ }^{3}$ Programming showcasing new or recent vids are regular, member-submitted fixtures in the schedule. As these depend on the number of submissions, the duration of these vidshows is flexible. For themed vidshows, curated by a VJ around a particular organizing principle, it has become normal to prepare a 45/50minute sequence of twelve-to-sixteen vids to fit into an hour programming slot. These are 'public' events open to all convention attendees, but with an expectation that the audience will be watching in silence, with each vid following the next in sequence. Early writing on media fandom noted a difference in the style and aesthetics of vids made for smaller and larger groups, drawing a distinction between 'convention' and 'living-room' vids, named for their exhibition spaces but indicating a change in mode of address and anticipated audience. Henry Jenkins reported that convention vids are 'broadly drawn to allow immediate recognition from a wide range of fans' who may not be paying close attention (1992: 238) whereas living room vids are 'made for a more select and analytic audience' (Jenkins 1992: 239) who know the source material well. From my experience at both annual vidding conventions, the range of media now used as vid source means that there is an assumption that audiences are attentive and prepared to enjoy a skilfully made vid for 
its own merits. Indeed, the present viewing culture at vid-focused conventions asks the audience to remain seated and silent during screenings, recalling the focus and intensity of Christian Metz's traditional 'silent, motionless' cinema spectatorship (1986: 96). However, during a vidshow, it is perfectly acceptable to laugh or cry with a vid, and to applaud between each work: it is talking and distractions that are forbidden.

In curating a vidshow, the immediate concern is to create an engaging experience for the audience: does it succeed in being fun, scary or thought-provoking? Does it effectively tell its story or make its argument? Does the sequence make sense? In creating this vidshow, I found that I was also very conscious of how I have used historical vidshow listings as reference points in my own research, and that I was likewise contributing to a historical record with this work. Much like a temporary exhibition in a museum or gallery, a vidshow exists beyond its screening slot. The convention programme containing a full listing for each vidshow is distributed to all convention members in print, and is also documented online in various forms. There is no central database of vids, making convention archives significant resources for reference and research. While the vidshow itself only existed for the duration of its programming slot, the record of that vidshow can endure past its first short life.

My vampire vidshow is named in reference to the title of the vampire film What We Do in the Shadows (Clement and Waititi, 2014). While this is mostly a convenient pun, it also points to the underground nature of vidding as a marginal practice and a hobby undertaken during evenings and weekends. VidUKon requires vidshow titles and descriptions months in advance of the content itself, making the title the first real step in curation. The next step was to assess my vid collection, largely assembled during my 
postgraduate research, to see what I already had on hand. ${ }^{4}$ There were five vids in my collection that I knew I had to include, and I had a promise of one premiere (a new vid to be made just for my show), leaving approximately six slots for other work. Finding the vids to complete the running time of this vidshow meant discovering vids that were new to me, which was itself an exciting proposition. I drew up my longer list through online vid communities, looking at historical vidshow listings, consulting inclu ding the annual Festivids event for niche and obscure fandoms, and crowdsourcing a longlist of possible source material out of which vids may have been made. I discuss some of the selection criteria below; Figure 1 contains the final running order of the vidshow. I am happy to report that the convention attendees all appeared to enjoy the vidshow.

\begin{tabular}{|l|l|l|l|l|}
\hline & \multicolumn{1}{|c|}{ Title of Vid } & \multicolumn{1}{|c|}{ Source } & \multicolumn{1}{c|}{ Vidder } & \multicolumn{1}{c|}{ Artist, 'Song Title' } \\
\hline 1 & Trouble & Interview with the Vampire (1994) & Bironic & Taylor Swift, 'Trouble' \\
\hline 2 & Respectable & Buffy the Vampire Slayer (1997-2003) & Charmax & Nellie McKay, 'Respectable' \\
\hline 3 & Not an Addict & Forever Knight (1992-1996) & Gianduja Kiss & K's Choice, Not an Addict' \\
\hline 4 & Down the Rabbit Hole & Kindred: The Embraced (1996) & Isagel & $\begin{array}{l}\text { Adam Lambert, } \\
\text { 'Down the Rabbit Hole' }\end{array}$ \\
\hline 5 & Living Dead Girl & Queen of the Damned (2002) & Kristen Harris & Rob Zombie, 'Living Dead Girl' \\
\hline 6 & Veins & Wir sind die Nacht (2010) & Violace & Bastille, 'Laura Palmer' \\
\hline 7 & Feel It In My Bones & The Vampire Diaries (2009-2017) & Trelkez & $\begin{array}{l}\text { Tiësto ft. Tegan and Sara, } \\
\text { 'Feel It In My Bones' }\end{array}$ \\
\hline 8 & Bela Lugosi's Dead & What We Do in the Shadows (2014) & Dogstar & CHVRCHES, 'Bela Lugosi's Dead' \\
\hline 9 & We're An American Band & Abraham Lincoln: Vampire Hunter (2012) & mresundance & $\begin{array}{l}\text { The Grand Funk Railroad, } \\
\text { 'We're An American Band' }\end{array}$ \\
\hline 10 & Carpe Diem & Ultraviolet (1998) & $\begin{array}{l}\text { Crancois-Paul Aïche, } \\
\text { 'The Opening' }\end{array}$ \\
\hline 11 & (This Isn't) Control & The Lost Boys (1987) & Sabaceanbabe & MS MR, 'This Isn't Control' \\
\hline 12 & Sunburn & Twilight (2008) & Obsessive24 & Muse, 'Sunburn' \\
\hline 13 & Personal Jesus & True Blood (2008-2014) & Killabeez & Marilyn Manson, 'Personal Jesus' \\
\hline 14 & Motherland & Byzantium (2012) & Beccatoria & Natalie Merchant, 'Motherland' \\
\hline 15 & You \& I Sail & Only Lovers Left Alive (2013) & Violace & $\begin{array}{l}\text { DJ Morgoth (Awolnation vs. } \\
\text { Seeed MashUp), 'You \& I Sail' }\end{array}$ \\
\hline
\end{tabular}

Figure 1: VidUKon, 'What We Vid in the Shadows', 2016. Courtesy of the author. 
I found many more vids about vampires than could fit into an hour. In a real sense, the first selection was done for me by the fans, limiting the scope of source material to what had already been vidded. By curating a vidshow I did not encounter all screen vampires, but the subset of screen vampires who have been addressed by this subculture. Even though some of the source material is from the 1980s and the 1990s, the vids have all been made in the last decade, and are contemporary perspectives on the older examples. In putting together my final programme, I could be selective: instead of finding the most apt order for the available vids, I had the latitude to make a more personal view. What these vids have in common is that they all are engaged in saying something true (to me) about the source material. As adaptations, they do not radically re-present their source material or work at an ironic distance, nor do they take clips out of context to produce new meanings not already present in the text either alone or in combination with other texts. ${ }^{5}$ While the form is altered and condensed, the vids' theme and approach is largely unaltered in how the vids adapt their source texts and any challenges or critiques that arise are meant to be understood as addressing the source text. Vids' mode of adaptation presents clips from the source material in a critical frame, detailing vidders' interpretations of that adapted text.

This means the vids themselves are relatively conservative adaptations as I chose vids that take their subjects seriously or that replicate the emotion with which I approach the source texts themselves. I did not want to make fun of vampire stories or to construct an ironic disavowal of their many pleasures. For example, in choosing a The Lost Boys (Schumacher, 1987) vid, I chose one that frames the protagonist's interaction with the vampire teens as a search for belonging, and therefore speaks to the film's themes, rather than an alternative that is structured around a playful homage to the film's recognizably 
1980s costume, hair and make-up choices. Conversely, while the Interview with the Vampire (Jordan, 1994) vid is certainly playful in its deployment of Taylor Swift's song - for example, having Louis confess to Lestat, 'I knew you were trouble when you walked in' to Louis's curtain-draped bedroom, intending to turn Louis into a vampire - it would be hard to argue that the vid is a departure from the film's narrative. The vid uses the song's regret over heartbreak 'a few mistakes ago' courtesy of a callous lover to reframe a film known for its queer subtext.

\section{Nostalgia and screen history}

Inspired by Holdsworth's work on nostalgia (and, particularly, its conservative expression as something safely distant from the past being remembered) as 'the dominant framework through which television remembers and refers to itself' (2011: 96), I propose that the vidshow is both a site of negotiating fan-favourite and cult canons of vampire shows and characters, and a mode of enacting memories of past television. Much like the BBC or other long-standing broadcasters repackage and redeploy their own production histories (which oftentimes coincide with significant world events), in what Holdsworth calls 'institutional nostalgia' (2011: 97), the vidshow offers a forum in which histories of fan canons can be negotiated. Holdsworth uses nostalgia as a frame to analyse television programmes that are about television's own history, arguing that these are ways of negotiating a 'safe return' to a remembered past, both of the medium itself and of a broader sense of the past as mediated through television's outputs. These instances of 'television about television' (Holdsworth 2011: 96) can be programmes such as clip shows, list shows, retrospectives or other ways of re-presenting old television in new frames. These strategies select particular 
bits of television on the basis of their being memorable; for example, charting the funniest sitcom moments, reminders of (television's coverage of) world events or resurrections of classic programmes. Of course, through this process of canonization - by selecting a segment for a clip show - television also constructs certain moments as worthy of memorialization.

I am aware that, in collecting and selecting vids for this show, I refined the existing canon of texts, arguing that certain vids, and therefore certain programmes and films, were memorable. As 'a form of longing that does not seek restoration' that is 'balanced in play between past and present, sameness and difference, recognition and estrangement' (Holdsworth 2011: 97), the vidshow offers a return to an array of media texts, re-presented in a frame for critical reappraisal and enjoyment. The vid form allows for returns to, and therefore can stimulate memories of, the experience of watching the source text and appreciations of the vids themselves. The latter is significant when the source is unknown to the viewer, where the vid-as-marginalia will be the entry point to this nostalgic framework. Importantly, it is thanks to innovations in distribution that enable fannish returns to these narratives - cult cinema screenings, syndication, home video releases, streaming services - that screen vampires can have a life beyond their first exhibitions or broadcast. A vid functions as an aide-memoire or as a cipher for personal and community histories of past media. These visible reminders function somewhat like the rooms occupied by Adam and Eve in Only Lovers Left Alive (Jarmusch, 2014), which Stacey Abbott describes as 'the tangible experience of immortality through the accumulation of loved objects that embody history' (2016: 159). Fan practice allows for being surrounded by our most treasured objects. 
Rather than capturing loss, these glimpses of past television (in vids alone, and through the organizing logic of vidshows) are used to spark emotions in the present. These emotions can certainly be based in recall and memory, but in the context of a vidshow are part of a sustained affective engagement with media. Coming back to Holdsworth's question about encounters with past television, 'Will it be how I remember?' - the answer is variable, but productively so. Each vid offers its own suggestion for how to remember programmes and films from our pasts. I chose to start the vidshow with that particular Interview with the Vampire vid, which uses a Taylor Swift song as its soundtrack, because the teen-pop feel of the song, used to imagine Louis's inner thoughts and regrets, reminds me so strongly of my teen memories of watching and loving that film. Teen angst was my lens for those characters and the vid speaks to my remembered mode of viewing. The vid is almost how I remember experiencing the film, but as articulated through a pop song that was released many years after the film and my first experiences of it. A vidshow offers a safe but critical return to past media, providing opportunities to evaluate and interrogate historical media. This also reveals that curation is not a dispassionate or an objective act, and this particular vidshow is an engagement with my own history with vids in media fandom.

What, then, is the history of screen vampires that I constructed through this vidshow? It is, bluntly, largely a white, male and Anglo-American history. While disappointing, it is not surprising: this reflects a general bias within fandom towards replicating normative structures of power and representation more broadly. Despite this failing, the vidshow does capture something of the range of genres beyond horror or the gothic that make use of vampire characters, and how hybrid genres use the recognizable 
tropes of the vampire. In seeking vids about vampires being vampires, I found many character studies where the vidders sought to articulate what made these characters appealing (or problematic). It is possible to claim the 'sympathetic vampire' label for many of the vampires represented, but in each vid this sympathy is clearly demonstrated through each vidder's chosen path through their source text. The vidders' sympathies - or, put another way, their engagement with the characters' complexities as more than monsters are clear in the vids themselves. There is a conversation in each work with the pleasures of screen vampires: desire and sensual engagement expressed extravagantly, pleasurably anti-social behaviour, finding family, finding love. The absence of Dracula is compelling, and was not a purposeful exclusion. While there are some vids that do exist about different adaptations of Dracula, none fit the feel of the vidshow I sought to create. In accidentally writing Dracula out of my history of vampires, it could be said that I collected together a wide scope of Dracula's descendants. These descendants are re-framed as central characters; however, while they are seen as outsiders within their fictional communities, they are themselves primarily white male Anglo-Americans (the dominant group in global media). This suggests an odd nexus wherein engagement and curation required recognizing and re-evaluating histories of racial and sexual representation, emphasizing both the pastness of these vids and the reality that they were made within the presentness of the last decade. Consequently, while this vidshow is a celebration of nostalgia and a history of vidding and vampires, it is also a relocation in the present of a continued need for intervention in communities of representation (as suggested by Rukmini Pande 2016). ${ }^{6}$

\section{Conclusion}


Leitch draws on Hutcheon's articulation of a 'palimpsestuous double consciousness' at play in experiencing an adaptation as an adaptation to explore the 'performative nature of adaptation' (2011: 13). If 'what makes an adaptation an adaption is the way it is performed' (Leitch 2011: 13), the performance of vids' adaptations is a critical one that contributes to media fandom's sense of its own history. A vidshow will typically include vids made from newer and older film and television sources, thereby becoming a forum to encounter screen histories: in this, vids perform historiography. Further analysis of vidshow curation can pose some fundamental questions of the media fan's relationship with media histories, as creator in their own right and the manner in which this poses questions of individuality (as this mediates the curator's own personal memories), a position of authority (in their inclusion and exclusion of vids) and their own role as audience for the vids themselves. Speaking from a position that straddles both academic objectivity and fan feeling, I am aware of creating a historical document about screen vampires that will persist, and this article documents a series of decisions leading to what is ultimately a personal take on this theme. The act of curating a vidshow balances the need to create a worthwhile experience for its audience, while engaging with the existing historiography of what has already been adapted into vids and was found worthy of memorialization. This may include replicating and intensifying existing failings in the equitable representation of race, gender and geographical diversity, where the opportunity to make curatorial inclusions can highlight these historical absences.

The VJ's role as creator, mediator and viewer - a point of introduction, a guide through the process and a participant - blurs boundaries functioning within these spaces. Therefore, further research is needed in theorizing these practices as forms of history and 
historiography, particularly in the context of museum and archive studies. In media fandom, I found that we are drawn to narratives that are about enduring love, about finding family and enjoying the excesses of these characters. But we are also, in my estimation, productively ambivalent about vampire narratives in general: with so many screen vampires to choose from, and so many ways of looking at vampires, we can engage with them both as polysemic metaphors and monsters that can be gory, goofy or both. With the vid form itself, and through the historicizing frame of the vidshow, we have a way of sharing with present and future audiences the ways stories about what these monsters have made us feel.

\section{References}

Abbott, Stacey (2016), Undead Apocalypse: Vampires and Zombies in the 21st Century, Edinburgh: Edinburgh University Press.

Auerbach, Nina (1995), Our Vampires, Ourselves, Chicago: University of Chicago Press.

Buffy the Vampire Slayer (1997-2003, USA: WB/UPN).

Clement, Jermaine and Taika Waititi (2014) What We Do in the Shadows, New Zealand/USA: Unison Films/Defender Films/Funny or Die/New Zealand Film Commission/Resnick Interactive Development. 
Coppa, Francesca (2008), 'Women, Star Trek, and the early development of Fannish vidding', Transformative Works and Cultures, 1: no issue number, n. pag.

Gray, Jonathan (2010), Show Sold Separately: Promos, Spoilers, and Other Media Paratexts, New York: New York University Press.

Holdsworth, Amy (2011), Television, Memory and Nostalgia, Basingstoke: Palgrave Macmillan.

Hutcheon, Linda (2013), A Theory of Adaptation, 2nd ed., New York: Routledge.

Jarmusch, Jim (2013), Only Lovers Left Alive, UK/Germany: Recorded Picture Company/Pandora Filmproduktion/Snow Wolf Production.

Jenkins, Henry (1992), Textual Poachers: Television Fans and Participatory Culture, London: Routledge.

Jordan, Neil (1994), Interview with the Vampire: The Vampire Chronicles, USA: Geffen Pictures. (2012), Byzantium, Ireland/UK/USA: Demarest Films/Lipsync Productions/Number 9 Films/Parallel Film Productions/WestEnd Films. 
Kindred: The Embraced (1996, USA: FOX).

Leitch, Thomas (2011), 'Vampire adaptation', Journal of Adaptation in Film \& Performance, 4:1, pp. 5-16.

McCabe, Colin (2011), 'Bazinian adaptation: The butcher boy as example', in C. McCabe, K. Murray and R. Warner (eds), True to the Spirit: Film Adaptation and the Question of Fidelity, Oxford: Oxford University Press, pp. 3-25.

Metz, Christian (1986), The Imaginary Signifier: Psychoanalysis and the Cinema, Bloomington: Indiana University Press.

Nadkarni, Samira (2017), 'Front and center: Examining black widow fanvids', in S. Ginn (ed.), Marvel's Black Widow from Spy to Superhero: Essays on an Avenger with a Very Specific Skill Set, Jefferson, NC: McFarland \& Company, pp. 38-51.

Ng, Eve (2008), 'Reading the romance of fan cultural production: Music videos of a television lesbian couple', Popular Communication, 6:2, pp. 103-21.

Pande, Rukmimi (2016), 'Squee from the margins: Racial/cultural/ethnic identity in global media fandom', in L. Bennett and P. Booth (eds), Seeing Fans: Representations of Fandom in Media and Popular Culture, New York and London: Bloomsbury Academic, pp. 209-20. 
Penley, Constance (1991), 'Brownian motion: Women, tactics, and technology', in C. Penley and A. Ross (eds), Technoculture, Minneapolis, MN: University of Minnesota Press, pp. $135-61$.

Renenet (2017), 'Major announcement about the future of VividCon - please read!', vividcon, 3 June, http://vividcon.dreamwidth.org/417106.html. Accessed 4 June 2017.

Ryder, Michael (2002), Queen of the Damned, USA/Australia: Village Roadshow Pictures/NPV Entertainment/Material Productions.

Schumacher, Joel (1987), The Lost Boys, USA: Warner Bros.

Stein, Louisa Ellen (2010), “What You Don't Know”: “Supernatural” fan vids and millennial theology', Transformative Works and Cultures, 4: no issue number, n.pag.

Stevens, E. Charlotte (2015), 'Exploring the vid: A critical analysis of the form and its works', Ph.D. thesis, Coventry: University of Warwick.

(2017), 'On vidding: The home media archive and vernacular historiography', in J.

Wroot and A. Willis (eds), Cult Media: Re-packaged, Re-released and Restored, London: Palgrave Macmillan, pp. 143-59. 
Supernatural (2005-present, USA: WB/CW).

True Blood (2008-14, USA: HBO).

Turk, Tisha and Johnson, Joshua (2012), 'Toward an ecology of vidding', Transformative Works and Cultures, 9: no issue number, n.pag.

VidUKon - UK Vidding Convention (2017), 'Database', http://www.vidukon.co.uk. Accessed 18 July 2017.

VividCon Vid Database (2017), http://vividcon.info. Accessed 18 July 2017.

\section{Contributor details}

Charlotte Stevens is a researcher with the Birmingham Centre for Media and Cultural Research, Birmingham City University. Her research interests include television history, fanvids and media fandom, and how archival practices affect public history.

Notes

${ }^{1}$ There is critical consensus that women are a majority in media fandom; see for example Penley (1991), Jenkins (1992), Coppa (2008). 
${ }^{2}$ Film and television are the most common source media, and narrative fiction predominates. However, effective vids have been made using still images, documentaries, adverts and recordings of digital game playthroughs.

${ }^{3} \mathrm{~A}$ comprehensive study of the history and evolution of the vidshow is beyond the scope of this article. VividCon, which first met in 2002, grew out of the Escapade convention (established 1991) and doubtlessly drew on practices established at Escapade. The proposed Fanworks Convention, planned for 2019, appears to take inspiration from VividCon's codification of screening and programming practices. Other fan conventions can and do have vidshows as part of their overall programming. The extent to which they follow the model established by Escapade will be an opportunity for fruitful further research.

${ }^{4}$ At the time of writing, this folder contains nearly 4000 files (albeit with some duplicates).

${ }^{5}$ I did not, for example, include the viral mash-up in which Buffy Summers 'stakes' Edward Cullen.

${ }^{6}$ My thanks to Samira Nadkarni for helping to articulate this point. 